\title{
ARTIGO
}

\section{Natureza jurídica do vínculo entre os motoristas e a empresa Uber: trabalho autônomo ou relação de emprego?}

Legal nature of the link between the drivers and the Uber company: self-employment or employment relationship?

Naturaleza jurídica del vínculo entre conductores y la empresa Uber: ¿trabajo autónomo o relación de empleo?

\section{Yuri Bindá Leite ${ }^{1}$ \\ Emerson Victor Hugo Costa de Sá Albefredo Melo de Souza Júnior ${ }^{3}$}

RESUMO: A tecnologia tem impactado sobremaneira a seara jurídica, notadamente no que tange às novas formas de trabalho. Dentre os aplicativos que demandam o labor humano para o desempenho dos serviços oferecidos apresenta-se o Uber, originalmente veiculado como sistema de caronas, mas que atualmente tem sido compreendido como um empreendimento voltado ao transporte individual de passageiros, com repercussões

1 Graduando em Direito pela Universidade do Estado do Amazonas.

2 Auditor Fiscal do Trabalho. Mestre em Direito Ambiental. Professor da Especialização em Processo Civil da Universidade Federal do Amazonas.

3 Professor efetivo do curso de Direito da Universidade do Estado do Amazonas. Especialista em Direito Processual Civil. Advogado. 
nos campos social e jurídico, principalmente quanto à análise da natureza do vínculo firmado com os motoristas. A presente pesquisa objetiva apurar o enquadramento jurídico mais apropriado a ser conferido a tais trabalhadores, autônomo ou empregado. São expostos com os cinco requisitos fundamentais do liame empregatício - pessoa física, subordinação, habitualidade, onerosidade e pessoalidade. A falta de jurisprudência consolidada a respeito da matéria impulsiona este artigo. Dentre as questões abordadas, tem-se a novel consideração da subordinação mediante o controle por meio de aplicativos, na modalidade chamada algorítmica, por comandos ou por programação. Essa espécie de tecnologia disruptiva de mão de obra tem como característica a camuflagem do elemento subordinação, em contexto que evidencia o controle por meios remotos, decorrente da compreensão do teletrabalho. As alternativas que propõem o distanciamento do obreiro em relação à legislação vigente negam direitos fundamentais sociais vinculados ao direito humano ao labor em condições favoráveis, mínimas e dignas de subsistência. $\mathrm{O}$ respeito à normatividade protetiva e ao primado do emprego demandam a configuração do vínculo laboral entre o empreendimento e os correspondentes motoristas. A abordagem metodológica seguiu a linha qualitativa, de aspecto exploratório e descritivo.

Palavras-Chave: tecnologia; livre concorrência; relação de emprego; subordinação.

ABSTRACT: Technology has greatly affected the legal area, notably with regard to th new forms of work. Among the applications that require the human work to perform the services offered is Uber, originally used as a system of hitchhiking, but which has now been understood as an enterprise aimed at individual passenger transport, with repercussions in the social and legal fields, mainly regarding the analysis of the nature of the bond established with the conductors. The research aims to determine the most appropriate legal framework applicably to such workers, either 
self-employed or employed. It was exposed the five fundamental requirements of the employment relationship - physical person, subordination, habituality, onerosity and personality. The lack of consolidated jurisprudence on the matter boosts this article. Among the issues addressed, one has the novel consideration of subordination by control through applications, in the so-called algorithmic mode, by commands or by programming. This kind of disruptive labor technology has as its characteristic the camouflage of the subordination element, in context that evidences control by remote means, resulting from the understanding of teleworking. The alternatives that propose distance the worker from the current legislation deny fundamental social rights linked to the human right to work under favorable conditions, minimum and worthy of subsistence. The respect to the protective normativity and to the primacy of the job demand the configuration of the labor bond between the enterprise and the corresponding conductors. The methodological approach followed the qualitative line, with an exploratory and descriptive aspect.

Keywords: technology; free competition; employment relationship; subordination.

\section{INTRODUÇÃO}

Nos tempos atuais, a tecnologia impacta de sobremaneira a seara jurídica, notadamente em razão do surgimento de novas formas de trabalho. Dentre os aplicativos que demandam o labor humano para o desempenho dos serviços oferecidos, apresenta-se o Uber. Originalmente veiculado como sistema de caronas, a prática de preços inferiores aos tradicionais meios de transporte particular ocasiona repercussões nos campos social e jurídico, sobretudo quanto à natureza do vínculo com os motoristas. 
Natureza jurídica do vínculo entre os motoristas e a empresa Uber: trabalho autônomo ou relação de emprego?

Os questionamentos a respeito da natureza jurídica da relação entre a empresa e os prestadores de serviços decorrem da possível visualização de concorrência desleal em comparação com outros do ramo de transporte individual. Ora o condutor funciona como empregado doméstico - motorista particular -; ora celetista - vinculado a um determinado empreendimento que se dedique ao transporte especial de passageiros; ou autônomo - taxista. Surge, então, o desafio de apurar o enquadramento jurídico mais apropriado conferido a tais trabalhadores.

Como autônomo, Vilhena (2005) entende o trabalhador livre de subordinação direta ao contratante, que dispõe livremente dos rendimentos auferidos e possui liberdade de organização e de execução do próprio labor. Em virtude do princípio da primazia da realidade sobre a forma (art. $9^{\circ}$ da Consolidação das Leis Trabalhistas - CLT) a existência de subordinação tem o condão de afastar eventual alegação de autonomia da relação trabalhista.

O reconhecimento do liame empregatício demanda a conjugação de cinco requisitos fundamentais (art. $2^{\circ}$ e $3^{\circ}$ da CLT): pessoa física, subordinação, habitualidade, onerosidade e pessoalidade. Para a análise em tela, percebe-se a subordinação como elemento cardeal para a identificação da natureza jurídica do vínculo.

Conquanto ainda não se note jurisprudência consolidada a respeito da matéria, há notícia de quatro decisões sobre o assunto. Em duas oportunidades ${ }^{4}$, negou-se o reconhecimento do vínculo empregatício, com a justificativa de que simplesmente se trata de uma nova tecnologia, não havendo a figura do empregador, propriamente

4 Processo 0011863-62.2016.5.03.0137, da 37 $\underline{\text { a }}$ Vara do Trabalho de Belo Horizonte e o Processo 000199546.2016.5.10.0111, da Vara do Trabalho do Gama-DF.

Laborare. Ano I, Número 1, Julho/2018, pp. 129-150. ISSN 0000-0000. http://trabalhodigno.org/laborare 
dito. Nas outras duas ocasiões ${ }^{5}$, reconheceu-se o liame empregatício. A instabilidade jurídica consistiu no fator preponderante que impulsionou a presente pesquisa.

De início, será abordado o contexto das tecnologias que introduziram essa nova categoria, do comando por meio de aplicativos e do surgimento da Uber. Avaliar-se-á se essa espécie de tecnologia disruptiva de mão de obra pode camuflar o elemento subordinação, ou se o contexto evidencia o controle por meios remotos, como mecanismo decorrente da compreensão do teletrabalho (art. 72-B da CLT).

Por conseguinte, serão apresentados o Direito Laboral como regulador das relações privadas, os conflitos que atribuem concorrência desleal à Uber, e as decisões alienígenas que tratam da natureza jurídica da relação (autônoma ou empregatícia) entre motoristas e empresa, além de outros aspectos conexos a tais abordagens.

\section{UBER E SUBORDINAÇÃO JURÍDICA}

O trabalho não se limita à produção de coisas, no sentido material. Agora, propõemse novas ideias como objetivo do labor, no prisma figurado, imaterial. Diferentemente do que propugna o taylorismo, gradativamente prepondera o trabalho imaterial. Entende-se que as máquinas assumirão, inclusive, as atividades que exigem pensamento, como a execução de tarefas administrativas e gerenciais; o controle da produção a partir da matéria prima até o marketing e a distribuição do produto final. Restaria uma hegemonia técnica e, consequentemente, o mercado de trabalho diminuiria. Uma deficiência dessa previsão consiste no fato de que a evolução dos meios tecnológicos gera novas formas de subordinação (Andrade, 2015).

5 Processo 0011359-34.2016.5.03.0112, da 33a Vara do Trabalho de Belo Horizonte e o Processo 1001492-33-2016502-0013, da 13 a Vara do Trabalho de São Paulo.

Laborare. Ano I, Número 1, Julho/2018, pp. 129-150. ISSN 0000-0000. http://trabalhodigno.org/laborare 
Natureza jurídica do vínculo entre os motoristas e a empresa Uber: trabalho autônomo ou relação de emprego?

Em meio a esse contexto, o mercado de trabalho do século XXI retoma características do mundo antigo ${ }^{6}$, como a mercantilização do labor humano. Tenta-se o mascaramento das relações de emprego mediante a suposição de autonomia do trabalhador, incutindose no obreiro essa falsa idealização. Novas tecnologias disfarçam os métodos de controle, mediante as figuras do provedor (aplicativo), do demandante (cliente) e do parceiro (prestador), como na economia on-demand (Signes, 2017).

A despersonalização da figura do empregador evolui, de tal modo que se dificulta a visualização de quem detém o poder de comando, tornando escasso o campo probatório para demonstrar a subordinação (Feliciano, 2013). Ainda que não se identifique precisa e claramente quem chefia, cresce o índice de subordinação mediante a utilização de novas ferramentas tecnológicas.

Para atender a uma grande massa de clientes e oferecer serviços mais dinâmicos, prestados por uma grande quantidade de trabalhadores, sem incidir no aumento do preço final, surgiu o crowd sourcing ou crowdwork, que consiste em descentralizar indefinidamente a prestação de determinado serviço (Signes, 2017). Há plataformas que prescindem do trabalho humano. Não é o caso da Uber, que depende da prestação de serviço de um motorista, para atendimento ao chamado do cliente.

O salário mínimo possui o intuito de proteger, além dos trabalhadores, o mercado em geral (Signes, 2017). Menores salários reduzem o poder aquisitivo dos empregados. Ao prejudicar o alcance de direitos sociais básicos e a renda mínima dos empregados, estimula-se a concorrência desleal. Os estabelecimentos obedientes à legislação

$6 \mathrm{Na}$ idade antiga, o trabalho era visto como algo ruim (tripallium), de modo que o único ofício valorizado era o relacionado à arte. O pagamento dava-se por meio de mercadorias. A liberdade demonstrava-se pela autonomia com contraprestação honrosa - honoraium. Qualquer tipo de atividade que demandasse força era tida pelo menosprezo (escravidão). Decorre dessa compreensão a relutância em afastar o serviço exercido do conceito de trabalho (Andrade, 2015).

Laborare. Ano I, Número 1, Julho/2018, pp. 129-150. ISSN 0000-0000. http://trabalhodigno.org/laborare 
protetiva são inviabilizados de concorrerem em igualdade de condições com os crowdsourcings, que reduzem ao mínimo os custos com pessoal. O afastamento dos direitos sociais fundamentais eleva o desemprego.

O surgimento do Uber deu-se no contexto de aumento das relações globalizadas e de renovação tecnológica. O aplicativo fora idealizado por Travis Kalanich e Garret Camp, empreendedores no Vale do Silício que buscavam uma nova e ágil alternativa ao transporte individual de passageiros (Leme, 2017).

Para o alcance desse objetivo, pensaram em uma aplicação que fornecesse informações sobre a pessoa responsável pelo transporte, o preço e o tempo de chegada do veículo até o local solicitado. Todavia, não pretendiam contratar motoristas, comprar carros ou alugar garagens, desvinculando-se do objeto de outros empreendimentos, que se amparavam na economia peer to peer. $\mathrm{O}$ advento da Uber orienta-se pela proposta de superação das formas arcaicas de trabalho (Leme, 2017).

O preço atrativo praticado pelo aplicativo cativou o mercado consumidor norteamericano. Em pouco tempo, a Uber alcançou a Europa e outros países da América, iniciando as operações no território nacional em 2014, no Rio de Janeiro (Leme, 2017).

A empresa utiliza um rígido e continuo sistema de avaliações. De início, o ingresso do motorista depende de uma série de requisitos. $\mathrm{O}$ interessado precisa comprovar a ausência de antecedentes criminais e a posse de um automóvel em boas condições de uso. $\mathrm{O}$ trabalhador submete-se a um treinamento, durante o qual recebe orientações sobre a forma padronizada de tratamento dos clientes (Leme, 2017).

A Uber remunera os motoristas com $80 \%$ do valor da corrida. A continuidade dos condutores depende da avaliação feita pelos clientes, que atribuem uma nota que pode 
Natureza jurídica do vínculo entre os motoristas e a empresa Uber: trabalho autônomo ou relação de emprego?

variar entre 1 e 5 . Para manter-se vinculado ao aplicativo, o motorista deve assegurar o índice igual ou superior a 4,6 como média de avaliação (Leme, 2017).

O sistema de monitoramento de atividades compele os motoristas a se colocarem disponíveis pelo máximo de tempo (Carelli, 2017). Viagens rejeitadas prejudicam a avaliação do motorista e podem redundar no desligamento. A situação impulsionou o protesto de um conjunto de motoristas da Uber na Califórnia, em 2015, contra as condições desumanas a qual estavam submetidos, vez que o alcance de uma remuneração digna mínima exigia o cumprimento de extensas e exaustivas jornadas. Nota-se como a tecnologia impacta diretamente a estrutura do trabalhado tradicional.

Segundo a concepção propugnada pelo empreendimento detentor do aplicativo, o motorista da Uber não possui vínculo trabalhista, pois segue uma jornada de trabalho flexível, que possibilita a escolha do horário que melhor atende às próprias necessidades, tal como um trabalhador autônomo.

Por outro lado, Chaves (2017) ressalta que a subordinação subsiste, ainda que de modo difuso, latente e diferido, contexto que justifica a extensão dos direitos celetistas. Seria o caso da aplicação da subordinação estrutural, modalidade na qual o trabalhador observa rigidamente os ditames do empregador; encontra-se obrigado a cumprir as normas impostas pelo contratante; e insere-se na sistemática do empreendimento, com ordens repassadas, diretamente ou não (Delgado, 2012).

O Direito do Trabalho remodela-se cotidianamente. Novas formas de trabalho exigem correspondentes e apropriados tratamentos jurídicos. A interpretação históricoevolutiva exerce papel fundamental na atualização de conceitos como o de subordinação, que ultrapassa a modalidade reticular e da dependência econômica para alcançar novos rumos e conformações jurídicas. O conceito atual de subordinação 
jurídica supera a ideia econômica, visualizada na relação do trabalho em que o trabalho consiste na única fonte de subsistência do empregado (Araújo, 2017).

A subordinação estrutural permite a abandonar esse viés puramente econômico para viabilizar a concepção de que a contratação do motorista da Uber exige a estrita obediência às regras de negócio, o transporte exclusivo de clientes indicados pelo aplicativo e o atendimento às normas de procedimento. Ainda que inexista o direcionamento de comandos diretos e expressos partidos de um superior hierárquico (subordinação clássica), a consolidação do controle via aplicativo revela um direcionamento ainda mais intenso, o que atualmente se tem concebido como subordinação algorítmica, por comandos ou por programação (Carelli, 2017).

Revoluções industriais sobrelevaram a autonomia da vontade. Os efeitos colaterais dessa liberdade ampliada são notados nas relações trabalhistas com extensas jornadas, exploração intensa das chamadas meias-forças (mulheres e crianças) e salários ínfimos. Disso resultaram inúmeros conflitos, que conformaram fontes materiais para o surgimento e consolidação do Direito do Trabalho (Bicalho, 2017).

De início, o Direito do Trabalho destinou-se à regulação das condições básicas de concorrência e à proteção da mão de obra. Como a autonomia da vontade mostrava-se insuficiente para salvaguardar o modo de exploração do trabalho, coube ao Estado instituir normas públicas, de natureza cogente, com o intuito de assegurar o mínimo existencial e impor balizas para viabilizar a livre concorrência (Bicalho, 2017).

A importância do Direito do Trabalho é observada nas grandes economias mundiais. A mão de obra de países como Alemanha e França está regida $80 \%$ pelo vínculo trabalhista, situação que contribui para o crescimento econômico, ao estimular o mercado consumerista e diminuir a concentração de renda (Bicalho, 2017). 
Para Bicalho (2017), empresas como a Uber reduzem as garantias trabalhistas, pois a exploração do trabalho alheio acontece sob condições extremas e sem a observância ao patamar civilizatório mínimo. A prática de negócio seguida pela multinacional tenta camuflar a natureza de vínculo empregatício e afastar a proteção dos trabalhadores. Tal contexto exige a atuação do Estado, para reafirmar a imperatividade das normas trabalhistas, que veiculam direitos fundamentais sociais.

\section{CONFLITOS LABORAIS NO DIRIETO COMPARADO}

Em 2014, a Alemanha suspendeu as atividades do aplicativo sob o fundamento de burla às normas tributárias e trabalhistas, de concorrência desleal e de necessidade de prévia autorização estatal para transporte de pessoas. Madri também sustou o aplicativo por oferecer serviço de transporte de pessoas sem licença pública (Lopéz, 2017).

Em 2015, o Tribunal de Milão paralisou cautelarmente as atividades da plataforma Uber, vez que acarretavam encargos superiores aos taxistas, em virtude do regime de tributação diferenciada, resultando em concorrência desleal. Em Barcelona tramita uma ação entre taxistas e Uber, amparada em discussões a respeito da concorrência desleal e da violação das leis trabalhistas (Lopéz, 2017).

$\mathrm{Na}$ França, houve aplicação de sanção administrativa à Uber por falta de recolhimento das cotas sociais, não obstante a existente subordinação jurídica entre os motoristas e a Uber. Tal decisão amparou-se no fato de os condutores encontrarem-se visivelmente sob o controle do aplicativo, exercido por meio do rígido regramento imposto pela empresa (Yárnoz, 2016).

Na Grã-Bretanha, a Uber argumentou que afigura-se como empresa de tecnologia, não de transporte, e que os motoristas cadastrados são autônomos e independentes, 
sendo livre a escolha de quando e onde trabalhar. Ainda assim, proferiu-se decisão reconhecendo o vínculo empregatício, com amparo nos depoimentos que demonstraram a subordinação jurídica e a ausência de autonomia (Osborne, 2016).

$\mathrm{Na}$ Inglaterra, em decorrência de ação judicial movida por ex-motoristas que pleiteavam o vínculo empregatício da empresa Uber, em outubro de 2016, reconheceu-se aos trabalhadores o direito de receberem salário mínimo e de possuírem uma jornada de trabalho protegida pelas leis trabalhistas (Johnston, 2016). Dentre outros motivos, o acórdão concedeu vínculo empregatício com base na obrigatoriedade de prestação de serviços aos passageiros indicados pela empresa; no recrutamento decorrente de submissão a entrevistas; na fixação de rota a ser percorrida; na definição das tarifas por parte da empresa; e na proibição de o motorista ajustar o valor com o passageiro.

Em virtude da clareza e da precisão argumentativa, confira-se o feixe de indícios da existência de liame empregatício, elencado por Frazão (2016):

Dentre os inúmeros aspectos explorados pelo Tribunal para justificar a grande ingerência da Uber sobre os seus motoristas e a consequente existência da relação de trabalho, encontram-se os seguintes: (i) o fato de a Uber entrevistar e recrutar motoristas; (ii) o fato de a Uber controlar as informações essenciais (especialmente o sobrenome do passageiro, informações de contato e destinação pretendida), excluindo o motorista destas informações; (iii) o fato de a Uber exigir que motoristas aceitem viagens e/ou não cancelem viagens, assegurando a eficácia desta exigência por meio da desconexão dos motoristas que violarem tais obrigações; (iv) o fato de a Uber determinar a rota padrão; (v) o fato de a Uber fixar a tarifa e o motorista não poder negociar um valor maior com o passageiro; (vi) o fato de a Uber impor inúmeras condições aos motoristas (como escolha limitada de veículos aceitáveis), assim como instruir motoristas sobre como fazer o seu trabalho e, de diversas maneiras, controlá-los na execução dos seus deveres; (vii) o fato de a Uber sujeitar motoristas, por meio do sistema de rating, a determinados parâmetros que ensejarão procedimentos gerenciais

Laborare. Ano I, Número 1, Julho/2018, pp. 129-150. ISSN 0000-0000. http://trabalhodigno.org/laborare 
ou disciplinares; (viii) o fato de a Uber determinar questões sobre descontos, muitas vezes sem sequer envolver o motorista cuja remuneração será afetada; (ix) o fato de a Uber aceitar o risco da perda; (x) o fato de a Uber deter as queixas dos motoristas e dos passageiros; e (xi) o fato de a Uber se reservar ao poder de alterar unilateralmente os termos contratuais em relação aos motoristas.

$\mathrm{Na}$ Espanha, a Inspeção do Trabalho de Catalunha investigou e concluiu que os motoristas da empresa Uber são empregados. O relatório sinalizou que os condutores são parte essencial para o segmento do aplicativo e carecem de qualquer espécie de organização empresarial (Gozzer, 2015).

Nos Estados Unidos, para fins de auxílio-desemprego declarou-se o vínculo empregatício da Uber com alguns motoristas, em mais de um estado. Em primeira instância, afastou-se a relação autônoma e reafirmou-se a empregatícia, tendo em vista que os motoristas são componentes essenciais para as operações comerciais regulares da empresa (Lehdonvirta, 2016).

Um dos casos mais interessantes ajuizados perante a Justiça Federal americana foi o caso Douglas O’Connor v. Uber, no qual a empresa propôs um acordo. Ainda que tenha se recusado a afirmar existente o vínculo empregatício, obrigava-se ao pagamento de 100 milhões de dólares. Todavia, o acordo não fora homologado judicialmente, em virtude da discrepância entre o valor da causa e a proposta.

A Recomendação 198 da Organização Internacional do Trabalho (OIT) surgiu com o intuito de incentivar e reforçar a atuação dos Estados membros a combaterem os vínculos trabalhistas disfarçados e implementarem políticas que afastem, por meio de leis e fiscalização, as barreiras impeditivas da imposição de normas e padrões humanitários provenientes da relação de emprego.

Laborare. Ano I, Número 1, Julho/2018, pp. 129-150. ISSN 0000-0000. http://trabalhodigno.org/laborare 
No art. 4\%, "a", preceituam-se os deveres do Estado de proporcionar à sociedade orientações sobre a identificação das relações de trabalho e emprego, exatamente com o objetivo de evitar que meios fraudulentos e disfarçados sejam impostos, como nos casos envolvendo a Uber. Nesse sentido, destaca-se que o parágrafo único do art. $6^{\circ}$ da CLT garante a igualdade entre os vínculos na modalidade presencial e de teletrabalho, equiparando-se os meios telemáticos aos pessoais, em termos de subordinação jurídica.

A Justiça brasileira apreciou o assunto por quatro vezes, tendo em duas decidido pela improcedência do pedido de reconhecimento do vínculo empregatício ${ }^{7}$. Nesses casos, elencou-se como justificativa o entendimento de que se trata apenas de uma nova tecnologia, não se encontrando a empresa na posição de empregadora. Nas outras duas ocasiões, reconheceu-se o liame empregatício ${ }^{8}$. Em tais casos, conclui-se que estavam manifestados os requisitos específicos da relação de emprego.

Essas últimas duas decisões consideraram configurados os requisitos previstos na CLT: pessoalidade, pelo fato de o cadastro e a matrícula serem personalíssimos; onerosidade, pois a Uber estipula a tarifa, recebe e repassa os valores ao motorista, retendo para si o percentual de $25 \%$; não eventualidade, em razão do constante incentivo para que os motoristas permaneçam em atividade, além da possibilidade de imposição de punições pela falta de disponibilidade e uso do aplicativo; e, por fim, a subordinação, configurada pelo repasse de comandos via aplicativo.

As decisões que negaram o vínculo laboral tiveram por fundamento a possibilidade de o condutor manter-se off-line (situação entendida como incompatível com a subordinação), de ser admitida a substituição por outro obreiro (o que afastaria o

7 Processo 0011863-62.2016.5.03.0137, da 37 a Vara do Trabalho de Belo Horizonte e o Processo 000199546.2016.5.10.0111, da Vara do Trabalho do Gama-DF.

8 Processo 0011359-34.2016.5.03.0112, da 33a Vara do Trabalho de Belo Horizonte e o Processo 1001492-332016-502-0013, da 13ำ Vara do Trabalho de São Paulo.

Laborare. Ano I, Número 1, Julho/2018, pp. 129-150. ISSN 0000-0000. http://trabalhodigno.org/laborare 
elemento pessoalidade). Deixaram de vislumbrar o requisito da não eventualidade, com base na informação de que os motoristas poderiam voluntariamente desligar o aplicativo, permanecendo afastados por até trinta dias, sem exclusão da plataforma. Ainda que excluídos, acata-se o recadastramento.

Veja-se, portanto, que a necessidade de análise da natureza jurídica do vínculo dos motoristas com a Uber não é exclusividade brasileira. Ao redor do mundo, a multinacional tem enfrentado questionamentos similares, sem que exista uma resposta universal para a questão. A solução depende da concepção de cada país a respeito da autonomia ou vinculação entre empregado e empregador. Tendo como ponto de partida a legislação pátria, estão presentes todos os elementos do vínculo empregatício?

\section{TRABALHO AUTÔNOMO OU VÍNCULO EMPREGATÍCIO?}

Após a análise da discussão do tema no direito comparado, observa-se que a polêmica ora estudada - natureza jurídica do vínculo dos motoristas com a empresa Uber - não é peculiar do Brasil. Ainda assim, a empresa mantém o discurso de que não se considera componente do ramo de transportes e que não há vínculo empregatício.

A realidade descrita fere o princípio internacional previsto nos artigos VI e XVI do Acordo Geral de Tarifas e Comércio (GATT) de 1994, da Organização Mundial do Comércio, no que tange ao princípio da concorrência leal e, também, ao preceito positivado no artigo XI da mesma Carta, relacionado à proibição das restrições quantitativas, cabendo internamente a cada Estado o estabelecimento da política de proibições e tributações destinadas à proteção da economia nacional.

No entanto, o artífice desse cenário deixou de ser o Estado. O posto está sendo assumido por uma empresa, que se utiliza de benefícios arbitrários para não tributar

Laborare. Ano I, Número 1, Julho/2018, pp. 129-150. ISSN 0000-0000. http://trabalhodigno.org/laborare 
corretamente. Criam-se, tacitamente, restrições e reduções de mercado para outros prestadores de serviços componentes do mesmo ramo.

Segundo Guimarães (2007), uma empresa de transportes "é o negócio por meio do qual uma parte - o transportador - se obriga, mediante retribuição, a transportar outrem, o transportado ou passageiro, e sua bagagem, de um lugar para outro". Caso reconhecida como sistema de transportes, a natureza jurídica empresarial poderia se aproximar do segmento que a originou. Provada a ausência dos requisitos celetistas, os motoristas poderiam ser classificados como "condutores autônomos de veículos rodoviários", em regime de colaboração/parceria, nos termos da Lei 6.094/74.

Entretanto, para classificá-lo como autônomo, seria necessário identificar no condutor uma pessoa com independência funcional, sem subordinação direta com o contratante e que dispõe livremente dos rendimentos auferidos.

A liberdade de organização do próprio trabalho é afastada em virtude da proibição de o motorista ser substituído, sendo o contrato de prestação de serviços personalíssimo. Consta em depoimento judicial de motorista da Uber que "não poderia colocar ninguém para ficar em seu lugar, que isso seria uma falta grave, com punição de bloqueio definitivo da plataforma" 9 .

O Projeto de Lei 28, que visa regulamentar o transporte remunerado privado individual de passageiros, exige que o veículo seja do próprio condutor, justamente para evitar que um mesmo carro seja compartilhado, reforçando o elemento pessoalidade ${ }^{10}$.

9 Processo 0011359-34.2016.5.03.0112, da 33ㅁ Vara do Trabalho de Belo Horizonte.

$10 \mathrm{Um}$ dos pontos mais atrativos da Uber consiste na possibilidade de o cliente conhecer antecipadamente 0 condutor. Desse modo, gera-se no consumidor a sensação de segurança na utilização do aplicativo. Solicitar o transporte, receber os dados de um motorista, e, no fim, ser conduzido por outro acarretaria a perda da confiabilidade do negócio.

Laborare. Ano I, Número 1, Julho/2018, pp. 129-150. ISSN 0000-0000. http://trabalhodigno.org/laborare 
A liberdade de disposição do resultado do próprio trabalho perde a possibilidade de existência no tocante ao regramento que a própria empresa Uber submete seus empregados, os quais são obrigados a aceitar as promoções implementadas pelo aplicativo, bem como a obedecer a todos os critérios de qualidade da empresa e somente conduzir os clientes mediados pela multinacional. Veda-se contratualmente o transporte de passageiros por conta própria.

Encontra-se atenuada a autonomia do prestador de serviços, na medida em que inserido o trabalhador na estrutura da empresa, devendo atenção aos procedimentos e regras por ela impostos. Um trabalhador independente e não subordinado deveria conhecer, ao menos, o valor da corrida do trajeto acordado. Isso não ocorre, pois é a empresa, não o motorista, quem negocia o preço com o cliente. Somente ao final do percurso o empregado terá acesso ao montante pago pelo serviço de transporte de passageiros. Depreende-se dessa abordagem que inexiste poder de barganha sobre o preço, sendo o operário plenamente vinculado às regras de negócio do aplicativo.

Por tais fundamentos, a natureza jurídica de profissão autônoma merece ser descartada, evidenciando-se a necessária compreensão sobre o verdadeiro instituto normativo aplicável à relação em exame. Em consonância com a Recomendação 198 da OIT (art. $4^{\circ}$, "a"), o art. $9^{\circ}$ da CLT preceitua que serão nulos de pleno direito os atos praticados com o objetivo de desvirtuar, impedir ou fraudar a aplicação dos preceitos contidos na Consolidação. Logo, a natureza da relação jurídica em questão mostra-se empregatícia, em razão da constatação dos cinco requisitos essenciais - pessoa física, subordinação, habitualidade, onerosidade e pessoalidade -, tal como adiante reforçado.

Sobre o requisito da pessoalidade, Delgado (2012) afirma ser "essencial à configuração da relação de emprego que a prestação do trabalho, pela pessoa natural, tenha efetivo caráter de infungibilidade, no que tange ao trabalhado". Quando um 
empregador contrata uma pessoa para assumir determinado cargo, é aquele indivíduo que tem a obrigatoriamente de cumprir o acordo, não sendo possível o trabalhador repassar tal incumbência a operário diverso.

De igual modo, o motorista da Uber tem a matrícula institucional personalíssima, sendo vedada a designação de outro condutor em seu lugar, restando assim comprovada a pessoalidade.

No plano objetivo, a onerosidade consiste na contraprestação pelo serviço executado. Por outro lado, o viés subjetivo compreende a expectativa do empregado de auferir recompensa pela atividade exercida. Em depoimento judicial, o ex-coordenador de operações da Uber no estado de Minas Gerais afirmou que, além do salário pago semanalmente para os motoristas, a empresa ainda possui um sistema de premiação ${ }^{11}$ :

[...] que próximo ao Carnaval, por exemplo, o motorista ativado que completasse 50 viagens em 3 meses ganharia $\mathrm{R} \$ 1.000,00$ (mil reais); [...] que no dia do protesto do taxista, no início de 2016, a empresa investigada já sabia que faltariam motoristas na cidade então programou uma promoção especial para o motorista que consiste em cumprir alguns requisitos, por exemplo, ficar online 8 ou mais horas, completar 10 ou mais viagens e ter uma média de nota acima de 4,7 e, então, o motorista ganharia $50 \%$ a mais de todas as viagens completadas nesse período e com esse padrão [...].

Além disso, todos os pagamentos que os usuários efetuam via cartão destinam-se ao empreendimento, que retém o percentual de $20 \%$, no UberBlack, e $25 \%$, no UberX. Semanalmente libera-se o pagamento para o motorista. Evidente, pois, a caracterização da onerosidade.

${ }^{11}$ Processo 0011359-34.2016.5.03.0112, da 33a Vara do Trabalho de Belo Horizonte.

Laborare. Ano I, Número 1, Julho/2018, pp. 129-150. ISSN 0000-0000. http://trabalhodigno.org/laborare 
A habitualidade ou não eventualidade corresponde a outro requisito do empregado em relação ao seu tomador. Não há necessidade de o trabalho ser prestado de modo contínuo, como no caso dos domésticos. Na verdade, tal como preceitua Cassar (2015), o vocábulo não eventual "caracteriza-se quando o tipo de trabalho desenvolvido pelo obreiro, em relação ao seu tomador, é de necessidade permanente para o empreendimento".

Outro motorista da Uber, em declaração judicialmente prestada afirmou “[...] que recebeu um e-mail que não se lembra a data dizendo que se não fizesse pelo menos uma viagem no prazo de uma semana, seria excluído da plataforma, mas não houve exclusão [...]"12, ponderações que reforçam a presença do requisito da não eventualidade.

Ainda nesse contexto, ressalta-se a existência do trabalho por tarefa, modalidade segundo a qual o emprego depende do resultado do serviço, não da jornada laborada. Nesse caso, analisa-se o produto do labor, não o tempo em que efetivamente o obreiro permaneceu nas dependências ou à disposição do empregador.

Outro ponto essencial para a caracterização do vínculo empregatício consiste na subordinação jurídica. Enquanto vigente a Medida Provisória 808 de 2017, a CLT reforçava expressamente, no art. 442-B, que a caracterização do elemento subordinação acarreta o afastamento da caracterização do trabalho como autônomo. A perda de vigência da norma em nada modifica essa compreensão, há tempos condensada na doutrina e jurisprudência laborais.

O Ministro Maurício Delgado (RR-119400-55.2007.5.03.0001) compreende a subordinação como elemento cardeal da relação de emprego, que pode se manifestar nas dimensões clássicas, "por meio da intensidade de ordens do tomador de serviços

12 Processo 0011359-34.2016.5.03.0112, da 33ㅁ Vara do Trabalho de Belo Horizonte.

Laborare. Ano I, Número 1, Julho/2018, pp. 129-150. ISSN 0000-0000. http://trabalhodigno.org/laborare 
sobre a pessoa física que os presta"; objetiva, "pela correspondência dos serviços deste aos objetivos perseguidos pelo tomador (harmonização do trabalho do obreiro a os fins do empreendimento)"; e estrutural, "mediante a integração do trabalhador à dinâmica organizativa e operacional do tomador de serviços, incorporando e se submetendo à sua cultura corporativa dominante".

Apresenta-se evidente a subordinação jurídica, tendo em vista fatores como o impedimento da adoção indiscriminada da postura de recusa de corridas, sob pena de exclusão da plataforma; a submissão a entrevistas como condição para ingresso no negócio; o controle patronal dos dados do empregado - inclusive seus antecedentes criminais; a rigorosa avaliação dos consumidores, utilizada como critério que pode resultar na demissão do condutor - análise enviada para o aplicativo, invisível para quem efetuou o trajeto; os constantes regramentos que vinculam o obreiro; bem como o fato de a companhia fixar previamente a rota a ser cumprida pelo autônomo.

Destaca-se, ainda, a conformação do controle algorítmico, considerando que o próprio art. $6^{\circ}$ da CLT estabelece a equivalência dos meios telemáticos de controle aos convencionais, para fins de subordinação jurídica. Com efeito, o teletrabalho (art. 75-B da CLT) literalmente afasta os motoristas daquela modalidade empregatícia, devido à característica eminentemente externa do labor desenvolvido.

A subordinação algorítmica decorre da evolução do conceito de controle, fenômeno social comum ao Direito do Trabalho. A cada geração, este ramo da Ciência Jurídica adapta-se às novas formas de trabalho. Disso depende o cumprimento do objetivo precípuo de salvaguarda da condição jurídica obreira. 
Desse modo, a comprovação dos cinco requisitos preconizados pelos art. $2^{\circ}$ e $3^{\circ}$ da CLT converge para que a natureza da relação jurídica da empresa Uber com seus motoristas afigure-se empregatícia.

\section{CONCLUSÃO}

A dimensão econômica do conflito indica que o caminho já esteja sendo trilhado, mas ainda está longe de uma solução definitiva. Ainda haverá muita discussão a respeito da natureza jurídica da relação entre a Uber e os motoristas cadastrados e aptos a operar e atender aos chamados mediados pelo aplicativo.

Nos países onde se instalou, o empreendimento tem enfrentado grandes dificuldades sobre tais questionamentos. Se há traços de autonomia, em igual ou maior proporção são observados mecanismos intensos e avançados de controle e limitação da liberdade de trabalho dos condutores.

A história do Direito do Trabalho e a evolução do conceito de subordinação indicam a necessidade de debate e reconhecimento da novel modalidade algorítmica, por comandos ou por programação. Prescinde-se da figura de um superior hierárquico dirigindo ordens aos motoristas. Hodiernamente, um aplicativo pode desempenhar esse papel, reunindo tranquila e precisamente todos os parâmetros de definição de conduta requerida e estimulada pelo empregador.

As alternativas que propõem o distanciamento do obreiro em relação à legislação vigente e sugerem a autonomia dos prestadores de serviço pessoal, oneroso, não eventual e subordinado podem gerar resultados negativos e a negação de direitos fundamentais sociais de labor em condições favoráveis, mínimas e dignas. 
Com respaldo na Convenção 198 da OIT e no art. $9^{\circ}$ da CLT, que repudiam expressamente as formas fraudulentas de desvirtuação das leis trabalhistas, o presente estudo não vislumbrou contornos suficientes de autonomia para o afastamento da natureza empregatícia da relação de trabalho entre a multinacional e os condutores. Enquanto presentes as premissas atuais de funcionamento do aplicativo, o respeito à normatividade protetiva e ao primado do emprego demandam a configuração do liame laboral entre o empreendimento e os motoristas.

\section{REFERÊNCIAS BIBLIOGRÁFICAS}

Andrade, E.G.L. (2015). Direito do Trabalho e Pós-Modernidade. São Paulo: LTr.

Araújo, W.M. (2017). Reflexões sobre a subordinação jurídica na era da economia sob demanda. In: Leme, A.C.P, Rodrigues, B.A., Chaves Júnior, J.R. (Coord.). Tecnologias disruptivas e a exploração do trabalho humano. Rio de Janeiro: LTR.

Bicalho, C.R. (2017). A natureza da onerosidade no contrato de trabalho: um estudo preliminar sobre uberização. In: Leme, A.C.P, Rodrigues, B.A., Chaves Júnior, J.R. (Coord.). Tecnologias disruptivas e a exploração do trabalho humano. Rio de Janeiro: LTR, 2017.

Brasil. Consolidação das Leis do Trabalho. Brasília, DF: Senado, 1943. Disponível em: <http://www.planalto.gov.br/ccivil_03/decreto-lei/Del5452.htm>. Acesso em: 20 mar. 2018.

Carelli, R.L. (2017). O caso uber e o controle por programação: de carona para o século XIX. In: Leme, A.C.P, Rodrigues, B.A., Chaves Júnior, J.R. (Coord.). Tecnologias disruptivas e a exploração do trabalho humano. Rio de Janeiro: LTR.

Cassar, V. (2015). Direito do Trabalho. 15. ed. São Paulo: Método.

Chaves, L.R.R.X. (2017). Informe sobre ações envolvendo a uber no direito comparado. In: Leme, A.C.P, Rodrigues, B.A., Chaves Júnior, J.R. (Coord.). Tecnologias disruptivas e a exploração do trabalho humano. Rio de Janeiro: LTR.

Delgado, M.G. (2012). Curso de Direito do Trabalho. São Paulo: LTr.

Feliciano, G.G. (2013). Curso Crítico de Direito do Trabalho - Teoria Geral do Direito do Trabalho. São Paulo: Saraiva. 
Natureza jurídica do vínculo entre os motoristas e a empresa Uber: trabalho autônomo ou relação de emprego?

Frazão, A. (2016). A decisão do Reino Unido sobre os motoristas da Uber: o que ela nos ensina? 1 jun. Disponível em: <https://jota.info/colunas/constituicao-empresa-emercado/decisao-reino-unido-sobre-os-motoristas-da-uber-o-que-temos-aprendercom-ela-01112016>. Acesso em: 25 abr. 2018.

Guimarães, P.J.S. (2007). Dos contratos de hospedagem de transporte, de passageiros e de turismo. São Paulo: Saraiva.

Gozzer, S. (2015). Trabajo dice que los chóferes de Uber son empleados de la firma. El País. 12 jun. Disponível em: <http://economia.elpais.com/economia/2015/06/12/actualidad/1434135569_865496.h tml>. Acesso em: 5 set. 2017.

Johnston, C. (2016). Uber drivers win key employment case. BBC News. 28 out. Disponível em: 〈http://www.bbc.com/news/business-37802386>. Acesso em: 02 jan. 2018.

Lehdonvirtal, V. (2016). Is the online gig economy growing? The iLabour Project. 20 set. Disponível em: <http://ilabour.oii.ox.ac.uk/is-the-online-gig-economy-growing/>. Acesso em: 6 set. 2017.

Leme, A.C.R.P. (2017). Uber e o uso do marketing da economia colaborativa. In: Leme, A.C.P, Rodrigues, B.A., Chaves Júnior, J.R. (Coord.). Tecnologias disruptivas e a exploração do trabalho humano. Rio de Janeiro: LTr.

Osborne, H. (2016). Uber loses right to classify UK drivers as self-employed. The Guardian. 28 out. Disponível em: <https://www.theguardian.com/technology/2016/oct/28/uber-uktribunal-self-employed-status>. Acesso em: 10 dez. 2017.

Signes, A.T. (2017). O mercado de trabalho no século XXI: on-demandeconomy, crowdsourcing e outras formas de descentralização produtiva que atomizam o mercado de trabalho. In: Leme, A.C.P, Rodrigues, B.A., Chaves Júnior, J.R. (Coord.). Tecnologias disruptivas e a exploração do trabalho humano. Rio de Janeiro: LTR.

Vilhena, P.E.R. (2005). Relação de emprego. São Paulo: LTr.

Yárnoz, C. (2016). Primeiro protesto de motoristas do Uber na França faz Governo mediar o conflito. El País. 20 dez. Disponível em: <http://brasil.elpais.com/brasil/2016/12/19/economia/1482164970_634000.html> Acesso em: 21 dez. 2017.

Laborare. Ano I, Número 1, Julho/2018, pp. 129-150. ISSN 0000-0000. http://trabalhodigno.org/laborare 